\title{
VIOLÊNCIA E PERVERSIDADE DISCURSIVA
}

VIOLENCE AND DISCURSIVE PERVERSITY

\section{DOI 10.20873/uft2179-3948.2021v12n1p6-24}

\section{Sírio Possenti ${ }^{1}$ Hélio Oliveira ${ }^{2}$}

\begin{abstract}
Resumo: Este artigo analisa alguns aspectos da polêmica envolvendo a acusação de genocídio dirigida ao presidente da República, durante a gestão da pandemia de covid-19, no Brasil. Depois de abordar o conceito de violência verbal, explora-se como um discurso aparentemente eugenista se vale de estratégias dissimulatórias, comuns em discursos atópicos (não aceitos pela sociedade, em geral), para nublar seu potencial violento e apresentar-se como defensor do bemestar social, ao mesmo tempo em que incita atos antidemocráticos, causa agressões e mortes.
\end{abstract}

Palavras-chave: Violência simbólica; Violência verbal; Polêmica; Atopia discursiva.

Abstract: This paper analyzes the polemics about the imputation of genocide crime against the President of the Brazil during the covid-19 pandemic. First, it covers the concept of verbal violence and then it explores how an apparently eugenic discourse makes use of dissimulatory strategies, common in atopic discourses (not accepted by society), to disguise its violent potential and so present itself as a defender of democracy, while inciting anti-democratic acts and leads to physical aggressions and death.

Keywords: Symbolic violence; Verbal violence; Polemics; Discursive atopy.

Vejo tanta notícia desagradável sobre a Irlanda, o Vietnã, os índios americanos, e, no que diz respeito ao Brasil, está tudo em paz. (General Emílio Garrastazu Médici, enquanto ocupava a presidência da república, na fase mais violenta da ditadura). ${ }^{3}$

Este trabalho tem duas partes. Na primeira, depois de breve contextualização, tratamos da questão da violência, com ênfase na violência verbal no Brasil atual. Na segunda, apresentamos - também brevemente - a polêmica sobre se o que ocorre no Brasil atualmente pode ser considerado genocídio. O que parece certo é que há um discurso eugenista capaz de

\footnotetext{
${ }^{1}$ Professor titular no Instituto de Estudos da Linguagem, IEL-UNICAMP, Campinas, SP; coordenador do Centro de Pesquisas Fórmulas e Estereótipos: Teoria e Análise (FEsTA), sirio@iel.unicamp.br

${ }^{2}$ Doutor em linguística, docente na UNIFEOB, São João da Boa Vista, SP. helio.oliveira@unifeob.pro.br

3 QUINTAL, Marisa. Pérolas da ditadura militar. Os filhos da dita. Blog, 20 fev. 2011. Disponível em: <http://bit.ly/3f1yOyY >, acesso em 22 mar. 2021
} 
implicar a morte em massa de milhares de pessoas, principalmente de grupos economicamente vulneráveis (o que acaba funcionando como argumento para a acusação de genocídio).

Partimos da hipótese de que se trata de um discurso atópico, pois não é associado a nenhuma instituição (se fosse, seria tópico), nem disputa um espaço de legitimidade entre outros discursos que circulam na sociedade (caso em que seria paratópico). Sendo atópico, isto é, existindo, mas como se não existisse, seu potencial de violência fica dissimulado, o que permite produzir enunciados sem as marcas típicas de violência verbal.

\section{Genocídio em plena democracia?}

No início de 2021, uma polêmica em torno da grave acusação de genocídio, dirigida ao presidente da república, ganha as grandes mídias do Brasil. Notícias reportam que uma denúncia formal envolvendo a questão, inclusive, foi recebida pelo Tribunal Internacional de Haia, embora não se saiba, até a produção deste artigo, se, de fato, será aberta uma investigação por parte do tribunal mencionado e qual será seu escopo - se os investigadores se restringirão a supostos crimes contra os povos indígenas brasileiros a partir de 2019, quando o presidente Jair Messias Bolsonaro (doravante, JMB) assume a presidência, ou se abrangerão sua atuação diante da pandemia, a partir de 2020.

Muitos casos de genocídio mancham a História da humanidade, legando aos responsáveis uma marca vergonhosa, uma vez que ser responsabilizado pela morte de populações inteiras é o crime mais grave que um governante possa cometer.

No Brasil, a circulação do termo não é nova. Pode-se citar, por exemplo, o livro de Abdias Nascimento (1978), O genocídio do negro brasileiro, sem contar as obras de diversos historiadores e sociólogos que falaram do genocídio dos povos indígenas pelas mãos dos colonizadores portugueses.

O tema reaparece, agora, quando os mortos pela covid-19 ultrapassam a espantosa cifra de 400.000 óbitos, subnotificados, segundo epidemiologistas, tornando o país o epicentro global da doença, e colocando-o acima de nações muito mais populosas, como China e Estados Unidos, na média móvel de mortes.

O termo "genocídio", embora fosse empregado, a princípio, para identificar a morte sistemática de grupos étnicos ou religiosos, tornou-se polissêmico, sobretudo após a Segunda Guerra Mundial, quando a palavra passou a referir "morte em massa", independentemente do perfil identitário das vítimas, segundo Thiago Amparo (apud BRANDINO, 2021), pesquisador de direito internacional e direitos humanos. De acordo com o autor, contribui para essa 
polissemia a relação tênue entre o conceito jurídico de "genocídio" e o de "crime contra a humanidade": enquanto o primeiro tradicionalmente requer a identificação de um grupo, o dolo contra um grupo específico sequer é exigido no segundo, embora a violência esteja sempre implicada em ambos os casos.

Na polêmica em questão, a opinião pública incendiou-se ainda mais quando os acusadores do presidente passaram a ser sistematicamente conduzidos a delegacias e indiciados com base na Lei de Segurança Nacional, promulgada em 1983, durante a ditadura militar. Alguns processos foram abertos pelo próprio Ministro da Justiça, André Mendonça, alegando crime contra a honra do presidente da República, embora essa ação devesse ser encaminhada, se fosse o caso, pelo Procurador Geral da República, o que acabou aumentando ainda mais o descontentamento em relação ao governo federal, no contexto dessa polêmica.

Uma interessante matéria da $\mathrm{FSP}^{4}$ oferece bom resumo da questão. A autora, Géssica Brandino, ouve especialistas em várias tendências, de modo que os diversos discursos podem aparecer. Apresentamos uma súmula. Em primeiro lugar, apresenta uma definição restrita de genocídio, tal como assumida pela ONU: trata-se de atos destinados a destruir, em todo ou em parte, um grupo nacional, étnico, racial ou religioso. Denúncias a tribunais internacionais seguem esta concepção, que, na matéria, é apoiada por diversos juristas. Um deles afirma não ver paralelo entre as ações do governo Bolsonaro e crime de genocídio assim definido. Outra jurista afirma que a população leiga não tem obrigação de conhecer este sentido, e que se trata de um uso retórico, destinado a chamar atenção para a gravidade da situação. E propõe que se tratem as ações do governo como crime contra a humanidade, posição reafirmada por outros entrevistados. Uma análise um pouco mais rigorosa (da professora Maristela Basso) diz que a acusação de genocida dirigida a Bolsonaro significa que ele "tem condições de entender as consequências de seus atos e, mesmo assim, ele nega, e, ao negar, deixa que isso aconteça". A matéria informa ainda que Basso denunciou Nicolás Maduro por genocídio e crimes contra a humanidade, que define como "crimes contra nós".

O objetivo deste artigo não é esmiuçar a questão do ponto de vista jurídico, mas investigar indícios do que motivou o emprego desse termo para qualificar o presidente como "genocida" (por exemplo, suas declarações e atitudes a respeito de temas decisivos para o controle ou a disseminação da doença, como o uso de máscara, o distanciamento social etc.), no que diz

\footnotetext{
${ }^{4}$ BRANDINO, Géssica. Bolsonaro genocida é retórica sem base jurídica, dizem especialistas. Folha de S. Paulo, 20 mar 2021, p. A8. Disponível em: 〈https://bit.ly/3sUZSDB >. Acesso em 10 abr. 2021.
} 
respeito às dinâmicas discursivas, ou seja, às relações de força que se estabelecem nos discursos em confronto.

Caberá aos tribunais brasileiros e, talvez, aos internacionais, avaliar se há um responsável por milhares de mortes e talvez aplicar algum tipo de condenação. Nos limites deste artigo, será examinado o papel dos discursos na percepção (e na dissimulação) de que o presidente possa ter cometido alguma forma de violência contra o povo do qual deveria "cuidar" e como essa percepção/dissimulação aparece em enunciados representativos do discurso do presidente e de seus apoiadores.

De qualquer forma, os julgamentos desses casos ganhariam muito se considerassem a participação dos discursos - suas especificidades e mecanismos de ação/dissimulação, continuamente descritos por linguistas e analistas do discurso - no desenrolar das grandes questões contemporâneas e na manipulação dos atores sociais.

\section{Violência(s) e discurso}

O conceito de violência varia bastante conforme o campo que o mobiliza, a ponto de alguns sociólogos e psicólogos preferirem empregar o termo sempre no plural (MARIN, 2002). Parece haver relativo consenso, entretanto, de que a violência não se resume a agressões físicas, mas abrange a violência psicológica e verbal, para citar as principais concepções, bem como forma menos visível de violência, a simbólica.

A violência dita legítima é a exercida por instituições de Estado (exército na guerra, justiça limitando "direitos", como o de ir e vir, polícia reprimindo). É considerada legítima porque se exerce segundo balizas legais, sejam os tratados internacionais, sejam as leis de cada país. Eventualmente, como se sabe, certas ações são objeto de controvérsia: como exércitos tratam prisioneiros de guerra, como policiais tratam manifestantes ou presos, como juízes aplicam determinadas leis etc.

A violência psicológica se realiza tipicamente por meio de palavras agressivas, amedrontadoras e humilhantes. É assim classificada quando exercida por alguém mais poderoso e próximo (por isso nem toda a violência verbal é violência psicológica). Pode não levar à violência física, mas nem por isso é menos significativa. Afeta, frequentemente, pessoas colocadas em posição de fragilidade, como crianças, mulheres e subordinados.

A violência simbólica é certamente a forma menos percebida de violência. Mauger (2017), em verbete sobre o tema, diz que a razão pela qual os "dominados" de todos os tipos não se revoltam é o medo da "repressão policial, militar, parental, marital", que percebem como 
"inscrita na ordem das coisas" (p. 359). A palavra "naturalização", que é "a transformação da história em natureza", segundo Bourdieu 1998 (p. 12), resume o fato de que uma instituição histórica pareça natural e, então, necessária. A questão da violência simbólica foi tratada por diversos pensadores, mas Bourdieu introduz uma novidade, segundo Mauger: "o conceito se aplica a todas as formas brandas de dominação que conseguem ganhar a adesão dos dominados” (p. 360). É uma violência oculta, cuja imposição passa pela linguagem, nas justificativas "religiosas", "naturais", "eruditas", e cuja eficácia deriva das aparentes vantagens para os dominados. Provavelmente a obra de Bourdieu em que este fato é mais convincentemente tratado é A dominação masculina (BOURDIEU, 1998). O combate à violência simbólica consiste em primeiro lugar em "reconstruir a história do trabalho histórico de des-historização" (1998, p. 136), ou seja, em demonstrar que não se trata de uma relação natural, mas historicamente construída.

Quanto à violência verbal, Van Dijk (1995) adverte que o dualismo reducionista entre "meras palavras" e "ações reais" tem consequências bastante concretas. Para este autor, uma evidência de que as palavras não são inofensivas é o fato de,

em muitas nações, o crescimento de agressões "apenas" com palavras contra imigrantes, refugiados e minorias, nos discursos político e midiático, encorajar discriminação, legitimar desigualdade e violar os direitos de milhões de pessoas (1995, p. 307, tradução nossa).

Van Dijk acrescenta que "formas simbólicas e verbais de violência podem ferir a liberdade de outros tanto quanto um ataque físico" e conclui: "Direitos humanos dizem respeito não só ao corpo das pessoas, mas também às suas mentes, que podem ser feridas ou manipuladas como consequência de uma agressividade discursiva" (VAN DIJK, 1995, p. 308, tradução nossa).

Abordando especificamente a análise da violência verbal, Ruth Amossy (2017) estabelece alguns critérios identificadores: traços retóricos de desconsideração e ridicularização do outro, estratégias de polarização/demonização do outro, enunciados marcados por "sentimentos violentos que se inscrevem em marcas lexicais, sintáticas e prosódicas", bem como na dimensão pragmática que leva a "interrupções no turno de fala do outro", e a uma "assertividade

\footnotetext{
${ }^{5}$ Um caso exemplar é o maninterrupting, neologismo cunhado para identificar as interrupções das falas de mulheres por parte de homens, uma forma explícita de desvalorização das mulheres. Um exemplo notável foi a entrevista de Manuela D’ávila, então pré-candidata à presidência da república, no programa Roda Viva, em que ela foi interrompida 62 vezes, enquanto outros entrevistados o foram muito menos: Ciro Gomes, 8 vezes, e Guilherme Boulos, 10 vezes, de acordo com o Portal UOL.
} 
peremptória (...) como uma demonstração de força que prescinde de justificativa", além da presença de insultos e de incitação à violência física (2017, p. 169-172).

Esse caráter inflamado, que também pode ser caracterizado como "discurso do excesso", movido pela "paixão do ódio" (BARROS, 2015), aparece nos excertos a seguir.

E1. Eu acho uma pena que essa imprensa mequetrefe que a gente tem aqui no Brasil fique dando conta de cobrir apenas a máscara. Ah, a máscara, está sem máscara, está com máscara. Enfia no rabo, gente, porra! A gente está lá trabalhando, ralando. (...) Fica esperto, você, retardado mental, que fica falando que o problema são os filhos, cadê o Queiroz, pagou apartamento de 50 mil em dinheiro. Seu animal, larga de ser peão nesse tabuleiro de xadrez chamado política, começa a pensar um pouquinho, e vê o perigo que tá por vir aí, como o sistema trabalha, porque não dá ponto sem nó. (...) E o lockdown não funciona em lugar nenhum do mundo (Senador Eduardo Bolsonaro, em uma de suas lives) ${ }^{6}$

E2. Não adianta fugir disso, fugir da realidade. Tem que deixar de ser um país de maricas. Olha que prato cheio para a imprensa. Prato cheio para a urubuzada que está ali atrás. Temos que enfrentar de peito aberto, lutar. Que geração é essa nossa? (...) Tudo agora é pandemia! Tem que acabar com esse negócio, porra! (Presidente da República, JMB, em uma declaração pública a apoiadores civis). ${ }^{7}$

Marcas de desconsideração/ridicularização do outro, bem como a presença de insultos, podem ser encontradas no excerto-1 (E1), em "mequetrefe", "retardado mental", "animal" e, no excerto-2 (E2), "urubuzada" e "maricas", para se referir à imprensa e aos críticos do governo federal. A referência ao urubu, uma ave necrófaga, tem um caráter particularmente acintoso e infame. Ao comparar os jornalistas e outros atores sociais, que confrontam o presidente exibindo o crescente número de mortos pela covid-19, cobrando-lhe ações de controle da pandemia, o chefe do poder executivo rebaixa o interesse legítimo desses cidadãos aos hábitos alimentares do urubu, animal conhecido por se alimentar da carne de cadáveres. Na declaração em E2, além do rebaixamento do trabalho da imprensa e dos adversários políticos, há um profundo desprezo pelos brasileiros que perderam suas vidas na pandemia.

Outros traços de violência verbal são as asserções peremptórias, movidas pela "paixão do excesso" (na perspectiva discursiva, determinadas pelas injunções do discurso ao qual o enunciador está submetido), como as exclamações em E1 “Enfia no rabo, gente, porra!" e E2 “Tem que acabar com esse negócio, porra!”, bem como perguntas “Que geração é essa, nossa?”.

\footnotetext{
${ }^{6}$ MEGALE, Bela. Em live, Eduardo Bolsonaro manda as pessoas "enfiarem a máscara no rabo". O Globo. 10 mar. 2021. Disponível em: 〈https://glo.bo/329bzLM>, consultado em 30 mar 2021.

${ }^{7}$ GOMES, Pedro Henrique. Brasil tem de deixar de ser "país de maricas" e enfrentar a pandemia de "peito aberto", diz Bolsonaro. G1 - Política, 10 nov. 2020. Disponível em: 〈https://glo.bo/3e3ZjBI> . Consultado em 30 mar 2021.
} 
Trata-se de uma insinuação de que na geração atual há muitas pessoas covardes, pouco másculas, cuja antítese seria o "maricas", qualificação que rebaixa os homens (como se só existissem homens!) à posição de fraqueza que seria típica da mulher, segundo o estereótipo da mulher frágil ou do gay afeminado, construções estereotipadas que bebem na mesma fonte: sexismo e dominação patriarcal. Acrescentem-se as ameaças e declarações que visam causar insegurança/medo ("Fica esperto você, retardado mental" ... "começa a pensar um pouquinho e vê o perigo que tá por vir aí"), desinformação e justificativas redutoras e falsas ("a imprensa cobre apenas o uso da máscara", "o lockdown não funciona em lugar nenhum do mundo", “Tudo agora é pandemia!", em E1 e E2, negritos nossos).

Apesar de o atual presidente ser um notável exemplar de usuário de linguagem violenta ${ }^{8}$, as mídias digitais e as redes sociais fornecem todos os dias exemplos de que tal prática não é exclusividade de uma pessoa e mesmo de seus apoiadores. A "oposição", pelo menos no ambiente digital, também é pródiga em pronunciamentos agressivos. Vejam-se os exemplos seguintes, comentários de leitores sobre o bate-boca entre Gal. Ramos e Gal. Pazuello (E3 a E6) e sobre a notícia de internação por covid de empresário que promoveu almoço com artistas sertanejos e JMB:

Com bastante frequência, a linguagem da violência é empregada também pelos adversários (costuma-se caracterizar o atual período histórico como "polarização", que se manifestaria em grande medida pele agressividade dos discursos). Mais ou menos colhidos ao acaso, vejam-se traços dessa agressividade nos seguintes comentários a notícias políticas (os elementos grifados são representativos):

E3. Esse Pazzuelo foi o assessor mais fácil pro Bolsonaro encontrar e escolher: a cara de cãozinho sabujo dele se vê de longe, me dá nojo, é daqueles guaipecas que lambem o dono pra ganhar um osso.

E4. Os crápulas genocidas, todos tem que pagar pelos crimes contra o povo.

E5. Que se matem abraçados, mas antes larguem o osso para que civis competentes possam ainda salvar milhares de vidas. Este é o maior problema deste bananal. Os generais, sujeitos incompetentes que tem uma vaidade enorme. Não sei porque.... quantas batalhas, kkkkkkkkkkk.

E6. Cloroquina do kú dele e manda fazer arminha que passa. kkkkkkkkk

E7. Não desejo a morte de ninguém, enterrem esse corno vivo mesmo; em pé...para não ocupar muito espaço!!!!

\footnotetext{
${ }^{8}$ Ver especialmente Piovezani e Gentile (2020), sobretudo o capítulo "Bolsonaro fala às massas" (pp. 141-245).
} 

inferno.

E8. Força Covid! Leva essa bosta e se possível, leve todo bozobostista pra fazerem arminha no

Em linhas gerais, é possível identificar as marcas descritas por Amossy nos excertos mencionados: ofensas e palavras de baixo calão (E3, E4, E6, E7 e E8), comparação de pessoas com animais, em conotação humilhante, subserviente (E3 e E5), alusões à agressão física e à morte (E5, E7 e E8), traços de "paixão do ódio" e excesso, como o tom assertivo, típico de uma fala carregada de raiva "a cara de cão sabujo se vê de longe", "me dá nojo" (E3), "Que se matem abraçados" (E5), "Força Covid! Leva essa bosta" (E8); e um tom irônico, seguido da onomatopeia de riso: "quantas batalhas, kkkkkk" (E5, destacando o fato de os generais brasileiros não terem oportunidade para provar sua coragem em batalhas, portanto, não teriam de quê se orgulhar ou serem vaidosos) e "manda fazer arminha que passa... kkkkk" e "fazerem arminha no inferno" (E6 e E8, em referência ao gesto simulando uma arma de fogo, que JMB e seus seguidores costumam fazer, mas que não podem protegê-los da covid).

A violência verbal, por sua força ilocucional associada à ofensa e à humilhação, efeito de atos de fala marcados pela agressividade, pode ser facilmente identificada. Conforme anunciado na introdução, no entanto, este artigo analisa, também, outro tipo de enunciado. Trata-se, por hipótese, de uma forma de violência que acontece independentemente da presença de violência verbal e, inclusive, na maioria das vezes, sem as marcas verbais de agressividade, mas cujo resultado é nefasto.

\section{Discurso e responsabilidade enunciativa}

Os dados a seguir, tematizando os eventos apontados pelos acusadores do presidente como "evidências" do crime de genocídio, apontam para uma regularidade suficiente para caracterizar uma prática discursiva singular, que parece sempre redundar em violência: o circuito se inicia com uma declaração aparentemente não-violenta (sem os traços prototípicos da violência verbal), acompanhada frequentemente de atitudes e gestos (ênfases, tom assertivo, mas também risos e tom jocoso) que tornam ambíguo o sentido da declaração, para, em uma ocasião posterior, culminar em algum tipo de violência física.

Vejamos algumas declarações emblemáticas do fenômeno dissimulatório que queremos demonstrar. Elas abrangem o posicionamento de Bolsonaro em relação à pandemia e foram selecionadas por serem representativas dos principais tópicos na atual fase histórica, marcada pelas preocupações com o novo coronavírus: hospitalização dos doentes por covid-19, 
distanciamento social, uso de máscaras de proteção, uso de medicamentos sem eficácia para combater a doença, aumento expressivo de mortes, acusação de genocídio.

E9 Tem hospitais de campanha perto de você, tem um hospital público, né? Arranja uma maneira de entrar e filmar. (...) tem que fazer para mostrar se os leitos estão ocupados, ou não. Se os gastos são compatíveis, ou não. Isso nos ajuda. (...) Não sei o que acontece, o que querem ganhar com isso. Tem um ganho político dos caras, só pode ser isso. Aproveitando que as pessoas falecem para ter um ganho político e para culpar o governo federal. Não tem como impedir essa doença, o óbito. ${ }^{9}$

E10. Estou cometendo um crime. Vou fazer um churrasco no sábado aqui em casa. Vamos bater um papo, quem sabe uma peladinha... ${ }^{10}$

E11. Pessoal, começam a aparecer estudos aqui, não vou entrar em detalhe, né?, sobre o uso de máscaras, porque tudo deságua em crítica contra mim (...). Começam a aparecer os efeitos colaterais das máscaras. ${ }^{11}$

E12. Tem algum médico aí? A eficácia dessa máscara é quase nula! ${ }^{12}$

E13. Sabemos que mais de 100 mil pessoas morreram no Brasil que, caso tivesse sido tratado lá atrás com esse medicamento [hidroxicloroquina], poderiam essas vidas terem sido evitadas. ${ }^{13}$

E14. Chega de frescura, de mimimi. Vão ficar chorando até quando? ${ }^{14}$

E15. E daí? Lamento. Quer que eu faça o quê? Eu sou Messias, mas não faço milagre. ${ }^{15}$

E16. Não sou coveiro, tá? ${ }^{16}$

E17. Todos nós vamos morrer um dia. ${ }^{17}$

9 ADLER, Matheus. Bolsonaro recomenda invadir hospitais: "Arranja jeito de entrar e filmar". Correio Braziliense - Política. 11 jun 2020. Disponível em: 〈https://bit.ly/3s9NoaG >. Consultado em: 30 mar. 2021.

10 Matéria não assinada. Vírus verbal: frases de Bolsonaro sobre a pandemia. DW Brasil. Disponível em: $\langle$ https://p.dw.com/p/3eukV>. Acesso em 30 mar. 2021.

${ }^{11}$ FAGUNDES, Murilo. Sem evidências, Bolsonaro diz que usar máscara causa "dor de cabeça". Poder 360, 25 fev. 2021. Disponível em: 〈https://bit.ly/2QnqeAg >. Consultado em 30 mar. 2021.

12 Matéria não assinada. Bolsonaro diz que máscara tem eficácia quase nula; ciência aponta proteção. UOL, Notícias. 19 ago. 2020, colchetes adicionados. Disponível em: 〈https://bit.ly/3shedJS >. Acesso em 30 mar. 2021.

${ }^{13}$ MARCELLO, Maria Carolina. Sem provas, Bolsonaro diz que mortes no Brasil poderiam ter sido evitadas com uso de hidroxicloroquina. Reuters. 13 ago. 2020. Disponível em : 〈https://bit.ly/3skmLzQ〉. Acesso em 30 mar 2021.

${ }^{14}$ Matéria não assinada. Vírus verbal: frases de Bolsonaro sobre a pandemia. DW Brasil. Disponível em: $<$ https://p.dw.com/p/3eukV>. Acesso em 30 mar. 2021.

${ }^{15} \mathrm{Idem}$.

${ }^{16}$ TAJRA, Alex. Veja falas de Bolsonaro sobre o coronavírus. UOL. Notícias. 05 dez 2020. Disponível em: $<$ https://bit.ly/2PMJ18x >. Acesso em 30 de mar. 2021.

${ }^{17}$ Idem. 
E18. Agora é o quê? Agora eu sou aquele que mata muita gente, como é que fala? Genocida! Agora eu sou genocida! (...) Do que eu não sou culpado aqui no Brasil? ${ }^{18}$

Os excertos acima não incluem marcas típicas da violência verbal. Muitas foram proferidas em um tom de voz amigável, tranquilo (E9, E11, E16) e até alegre, entre risos (E10, E16, E18). Os casos em que o tom foi mais enérgico, ainda assim não denotavam a agressividade característica da ofensa, mas a aparente firmeza de quem se defende de uma injustiça, de quem enfrenta uma calúnia (E12, E14, E15, E17); a maioria das declarações é de repostas a jornalistas. Não se identificam palavrões ou termos que impliquem alguma forma de humilhação explícita. As palavras "frescura" e "mimimi” (que significa "choramingo", "lamúria"), por exemplo, beiram a infantilidade - são inadequadas ao decoro esperado de um presidente da república, mas de baixo caráter ofensivo, comparadas com outras.

Em que medida, então, elas se relacionam com o suposto crime de genocídio atribuído ao mandatário pela má condução do enfrentamento à pandemia? Haveria algum potencial violento em falas como as destacadas?

A noção de responsabilidade enunciativa (MOIRAND, 2011) ajuda a compreender o peso das declarações em questão. Ao entender que falar implica uma responsabilidade na construção da realidade social, Sophie Moirand observa que essa forma de ética

\begin{abstract}
se manifestaria no modo de nomear (designar, caracterizar) os fatos e acontecimentos, atores, suas ações e seus atos de linguagem, assim como o modo de representar seus dizeres: uma ética da responsabilidade implica efetivamente não se ter o direito de negligenciar as consequências de seus atos de linguagem, e não deixa de ter consequências, por exemplo, escolher entre "jovem" e "crápula", entre "estudante" e "anarquista", para designar os atores de um acontecimento (2011, p. 283).
\end{abstract}

Ao estudar o papel da imprensa na reprodução de certos discursos e no apagamento de outros, a autora põe em relevo as consequências daquilo que se diz publicamente. Em nossos exemplos, nem mesmo está em jogo, conforme dissemos há pouco, o emprego de palavras ofensivas como "crápula", mas as ações que redundam das afirmações de que a pandemia é apenas "mimimi" ou "frescura" (E14), que os leitos destinados às vítimas de covid-19 estão vazios (E9) e que medidas de proteção como a máscara e o distanciamento social não funcionam

\footnotetext{
${ }^{18}$ CARVALHO, Daniel. Bolsonaro brinca após 4.000 mortes: “Agora eu sou genocida”. Jornal de Brasília. 07 abr. 2021. Disponível em: 〈https://bit.ly/3uLdSRu〉. Acesso em 07 abr. 2021.
} 
(E10, E11, E12). As consequências de repetidas declarações como essas são funestas, apesar de proferidas em tom não agressivo.

A fala sobre filmar os leitos hospitalares, por exemplo, materializa o discurso negacionista de que o vírus não é tão contagioso nem tão letal quando diz a maioria dos epidemiologistas, pois, afinal, os hospitais de campanha não estariam lotados. A irresponsabilidade criminosa dessa fala, além de expor os próprios apoiadores ao risco de se infectarem com o vírus entrando em espaços contaminados, interferiu na rotina dos profissionais de saúde, já sobrecarregados, obrigados a interromper seus atendimentos para conter os invasores. Houve invasão e depredação de hospitais públicos, conforme fatos amplamente noticiados pela imprensa, logo após a declaração presidencial ${ }^{19}$, e enfermeiros chegaram a sofrer agressões físicas.

O negacionismo também aparece nas alegações de que o uso de máscara, recomendado pelas organizações de saúde, não é eficaz e até teria efeitos colaterais prejudiciais à saúde (E11, E12), na defesa da hidroxicloroquina como tratamento eficaz contra o coronavírus (E13), no incentivo às aglomerações (E10), na minimização das mortes (E14, E15, E16). Mais recentemente, em face da inquestionável catástrofe sanitária representada pelo elevadíssimo número de mortes, o negacionismo aparece na constatação da inevitabilidade da morte, o que desemboca na, ainda pior, naturalização da morte (E17). Nesse ponto, o discurso eugenista, até então diluído, sobrepõe-se ao negacionista, pois muitas mortes - talvez a maioria delas - são perfeitamente evitáveis, haja vista o fato de países mais populosos do que o Brasil não sofrerem uma média móvel de mortes tão alta quanto a nossa.

As consequências violentas dessas declarações são visíveis nas invasões e depredações de hospitais públicos, acompanhadas de agressões físicas a profissionais médicos e enfermeiros que trabalham nesses locais, fato mencionado há pouco, como também nas inúmeras agressões sofridas por funcionários do comércio por parte de clientes que se recusam a utilizar a máscara de proteção (como efeito do exposto em E11, sobre improváveis problemas das máscaras), nas frequentes aglomerações em festas e confraternizações (desdobramento de declarações representadas por E12) e nos casos de automedicação (eventualmente prescrita por médicos apoiadores do projeto bolsonarista) de hidroxicloroquina e outros itens do chamado "kit-covid" (a partir de indicações como a exposta em E13).

\footnotetext{
${ }^{19}$ HAMON, Gabriel. Um dia após incentivo de Bolsonaro, grupo invade ala da covid-19 em hospital do Rio. O Popular. Cidades. 12 jun. 2020. Disponível em: 〈https://bit.ly/3mJdmRf〉. Acesso em 05 abr. 2021.
} 
Em relação a esse último aspecto, o da incitação à automedicação por produtos ineficazes, o efeito "empírico" de repetidas declarações negacionistas (e, adiantando nossa interpretação, eugenistas) é constatado em falas como a de uma mulher, dirigida ao presidente, em uma de suas aparições públicas, que alegava ter sido curada da covid-19 graças às orientações de JMB: "Tomei cloroquina, tomei tudo o que o senhor recomendou", disse a apoiadora ${ }^{20}$. Diferentemente do que ela afirma, a própria Agência Nacional de Vigilância Sanitária (Anvisa) tem alertado para o aumento de $558 \%$ em notificações de efeitos adversos da hidroxicloroquina $^{21}$ - um caso semelhante, vale lembrar, foi o aumento do número de intoxicações por desinfetante após Donald Trump ter sugerido a ingestão dessa substância para combater o coronavírus. $^{22}$

Esses fatos dão contornos bem nítidos às consequências violentas das atitudes de líderes como JMB ao não levar em conta a responsabilidade enunciativa, para além da responsabilidade civil, legal, que recai sobre eles, resultando na morte da população, especialmente dos grupos mais vulneráveis. A violência emana, então, do caráter negacionista-eugenista desse discurso de JMB e de sua rede de apoiadores.

Enfatizando seu caráter eugenista, um exemplo adicional desse discurso, bem como de sua difusão por outros atores, é a decisão de Fernando Gomes, prefeito de Itabuna, Bahia, relativa a uma das pautas defendidas por JMB, a abertura do comércio em plena pandemia: “já mandei fazer o decreto, no dia 9 [o comércio da cidade] abre, morra quem morrer". ${ }^{23}$

Ainda sobre esse caráter, diretamente relacionado à morte em massa da população pobre e periférica (sem reservas financeiras próprias ou auxílio emergencial do governo que lhe possibilite manter-se afastada do transporte público e do trabalho, muitas vezes informal, nas ruas), um estudo desenvolvido na Faculdade de Saúde Pública da Universidade de São Paulo (USP) pelo Centro de Pesquisas e Estudos de Direito Sanitário (CEPEDISA) divulga, em janeiro de 2021, um boletim que confirma o papel do governo federal na infecção massiva e intencional de brasileiros. $\mathrm{O}$ trabalho analisou a produção e autorização de portarias, medidas

\footnotetext{
${ }^{20}$ Matéria não assinada. Bolsonaro diz que máscara tem eficácia quase nula; ciência aponta proteção. UOL, Notícias. 19 ago. 2020, colchetes adicionados. Disponível em: 〈https://bit.ly/3shedJS >. Acesso em 30 mar. 2021.

21 Matéria não assinada. Anvisa registra mortes por uso de "kit-covid". Isto é. Coronavírus. 05 abr. 2020. Disponível em: <https://bit.ly/32iYoI5>. Acesso em 05 abr 2021.

${ }^{22}$ LAMARQUE, Kevin. Casos de intoxicação por desinfetante crescem após sugestão de Trump. Veja online. 22 abr 2020. Disponível em: 〈https://bit.ly/3g7q5Mg>. Acesso em 30 mar 2021.

${ }^{23}$ SALGADO, Rodrigo. "Morra quem morrer", diz prefeito de Itabuna, na Bahia, ao anunciar a reabertura do comércio. Estado de Minas. 02 jul 2020. Disponível em: 〈https://bit.ly/3a9K0Xc〉. Acesso em 05 abr 2021.
} 
provisórias, resoluções, instruções normativas, leis, decisões e decretos do governo federal, assim como o levantamento das falas públicas do presidente, parar concluir que há

uma estratégia institucional de propagação do vírus, promovida pelo Governo brasileiro, sob a liderança da Presidência da República (...) com o propósito de desacreditar as autoridades sanitárias, enfraquecer a adesão popular às recomendações de saúde baseadas em evidências científicas, e promover o ativismo político contra as medidas de saúde pública necessárias para conter o avanço da Covid-19. (...) O Brasil ultrapassou a cifra de 200 mil óbitos em janeiro de 2021, em sua maioria mortes evitáveis por meio de uma estratégia de contenção da doença. Isto constitui uma violação sem precedentes do direito à vida e do direito à saúde dos brasileiros (VENTURA, 2021, p. 6 e 7).

Confrontando os resultados dessa pesquisa com os excertos aqui analisados, podemos dizer que a estratégia de disseminar o vírus se vale dos temas mencionados nos enunciados, como exaltar a valentia das pessoas, que não deveriam ter medo do vírus, ao mesmo tempo em que se cria a falsa ilusão de que há medicações capazes de curar ou diminuir os riscos de infecção, além de minimizar o perigo da doença e naturalizar as inegáveis mortes.

Chegamos, assim, a um aparente impasse, objeto do último tópico deste artigo: se está em curso um discurso eugenista endossado pelo presidente, como a maioria da população e das instituições não se indignam e, ainda mais, não se mobilizam para deter o curso de uma sistemática política de morte?

Ocorre que, como dissemos, está em curso um fenômeno discursivo que opera dissimulando o caráter negacionista-eugenista de um discurso que tem sistematicamente causado a morte evitável de milhares de pessoas. Decorre dessa dissimulação a ideia de perversidade discursiva.

\section{A perversidade discursiva}

Ao perceber que nem todos os discursos desfrutam da mesma legitimidade no espaço social, Maingueneau (2010) propõe a distinção entre discursos tópicos e atópicos (além dos não tópicos, cujo corpus é construído pelos pesquisadores). Os primeiros têm pertencimento institucional (discurso publicitário, discurso médico, entre outros casos), enquanto os segundos não teriam um "lugar" de existência próprio, legítimo, sendo rejeitados pelo corpo social, como o discurso pornográfico, seu exemplo mais claro. Pertencem à mesma categoria discursos ligados a práticas sexuais tabu, como a pedofilia, e a práticas religiosas interditas, como o satanismo, por exemplo. Propomos somar o discurso eugenista a estes últimos. 
O fato de serem considerados inaceitáveis pela maioria da sociedade não significa que não congreguem apoiadores, pois é justamente dessa existência paradoxal que eles se alimentam. Para Maingueneau (2010), é impossível que esses discursos não existam e é impossível que eles existam:

O primeiro impossível é da ordem do fato: diante do que é uma sociedade, é inelutável que esses enunciados serão produzidos nela. O segundo impossível é da ordem da norma: se esse discurso tivesse pleno direito de cidadania, então não haveria sociedade possível (2010, p. 24).

É característica do enunciador desses discursos manifestar-se por meio de um ethos híbrido, instável, no caso em questão, marcado pela alternância entre um ethos violento, cruel e um ethos de razoabilidade, ponderação e comprometimento com o bem-comum, como veremos nos excertos a seguir. Essa alternância entre o ethos de "crueldade" e o de "bondade", no mesmo enunciador, foi comparada com a natureza instável do protagonista de $O$ médico e o monstro, em Oliveira (2019), o que, por sua vez, coloca em cena uma inversão semântica em que, ao invés de figurar como agressor, ele aparece em determinados momentos como vítima (Oliveira, 2021).

A transformação (temporária) de agressor em vítima permite ao enunciador de um discurso atópico negar o traço socialmente indesejável de sua identidade. Por exemplo, o racista, o pedófilo, ou, no caso em epígrafe, o eugenista, jamais se assumem publicamente, uma vez que negam serem praticantes desses atos. A negação do dolo, assim, é uma característica adicional presente nesses enunciados.

A partir dos casos apresentados na coletânea em análise, a negação de qualquer motivação e consequência violenta e/ou genocida parece ser o traço que mais se destaca no processo de dissimulação. Limitando-se a um dos eventos já citados, a incitação à invasão de hospitais (E9), vejamos como esse disfarce acontece.

E19. Bolsonaro não mandou "invadir" hospitais, mas fotografar e filmar leitos vagos em hospitais públicos, sobretudo hospitais de campanha, para comprovar que existem informações falsas sendo levadas ao público. ${ }^{24}$

\footnotetext{
${ }^{24}$ POLÍBIO, Braga. Zero Hora produz fake ao dizer que governadores mandaram carta de protesto a Bolsonaro.
} Blog Políbio Braga. 13 jun. 2020. Disponível em: 〈https://bit.ly/2OQQC5e〉. Consultado em 30 mar. 2021. 
E20. Só um bandido ou um doente mental para minimamente crer que o Presidente incentivou invasão a hospitais ao invés de entender que o citado foi para que cidadãos cumpram seu direito de fiscalizar os gastos públicos. ${ }^{25}$

Submetido às injunções do discurso que precisa ser dissimulado, os defensores da estratégia bolsonarista sacrificam a lógica com a afirmação de que é possível "fotografar e filmar leitos de hospital" sem ser necessário entrar no hospital (E20). Os hospitais de campanha são destinados ao tratamento de pacientes vítimas da covid-19, uma doença altamente infecciosa, como se sabe, o que restringe a circulação de pessoas no interior dos quartos desses pacientes para evitar expô-los a outras infecções, devido a já estarem bastante debilitados, e principalmente para impedir que o vírus se espalhe a partir dos pacientes infectados. Não se trata, obviamente, de quartos que estão abertos ao público, à disposição de quem queira fotografá-los. A palavra "invasão" aparece entre aspas, para marcá-la como o discurso do outro, não endossado pelo locutor, deslocando a ênfase para os atos de "fotografar, filmar" e “comprovar" supostas informações falsas.

O excerto E13 também inclui uma falha argumentativa ao relacionar duas ações sem qualquer nexo ou relação de causa-consequência: a invasão de civis a uma ala hospitalar restrita por alto risco de contaminação biológica e o processo de fiscalização dos gastos públicos.

Tal funcionamento discursivo, ilustrado em E12 e E13, não se resume à negação do potencial violento/criminoso da declaração em E9, feita em rede nacional. Também dissimula qualquer caráter negativo da incitação à invasão, promovendo uma espécie de inversão semântica na qual esse ato ganha conotação positiva, transfigurando-se no inocente ato de fotografar/filmar e na legitimidade de denunciar informações falsas e fiscalizar gastos públicos, exemplos de ações cidadãs. Assim, a dissimulação permite observar um processo de polarização semântico-discursiva em que o incitador e os praticantes de violência são situados em um registro positivo e seus adversários e críticos em um polo negativo, qualificando-os como "bandidos" ou "alienados" (porque estariam acreditando em informações falsas) ou como maus cidadãos (porque não teriam coragem de agir em prol do bem comum, "fiscalizando" os gastos públicos e "denunciando" o mau uso da verba destinada à saúde).

A invasão de hospitais e as agressões contra profissionais de saúde, cometidas por terceiros e não pelo presidente, poderia ser considerada apenas uma infeliz coincidência.

\footnotetext{
${ }^{25}$ MAZIEIRO, Guilherme. Carlos diz que só "bandido" crê que Bolsonaro incentiva invasão a hospital. UOL Política, 14 jun. 2020. Disponível em: <https://bit.ly/3e226LQ>. Consultado em 30 mar. 2021.
} 
Entretanto, como fatos similares começam a ocorrer sistematicamente, fica claro que as ações são consequências da "obediência" à sugestão do chefe...

Um último e breve exemplo das consequências violentas de uma declaração aparentemente não violenta é a constante propaganda contra o uso de máscara por parte do presidente, de seus filhos e de políticos apoiadores, acompanhada do aumento de casos de violência cometida contra funcionários do comércio por clientes que se recusam a utilizar a máscara nos estabelecimentos, em dezenas de cidades brasileiras, conforme uma rápida busca em portais de notícia pode confirmar.

A dissimulação da violência eugenista presente no modo como o governo federal tem lidado com a pandemia no Brasil envolve, assim, a tentativa de transformar práticas autoritárias, negacionistas e eugenistas em ações cruelmente apresentadas como benéficas. Chega-se à perversidade de zombar das mortes (“E daí?", "Não sou coveiro!", "Vão ficar chorando até quando?") e rir da terrível acusação de genocídio (“Agora eu sou aquele que mata muita gente, como é que fala? Genocida!").

Consideramos essa dissimulação da violência uma forma de perversidade discursiva: trata-se de um funcionamento discursivo que permite ao enunciador de discursos atópicos atuar como se fosse inofensivo, mas, mesmo assim, inspirar ataques e agressões, nublando a relação entre o que se diz e o que se pratica, disfarçando, assim, sua virulência, que só pode ser percebida quando se examina o efeito dos discursos nas práticas violentas, ora mais simbólicas e psicológicas, ora física, culminado em muitos casos de morte.

A instabilidade gerada pela atopia do discurso em questão, cuja identidade não se limita às faces negacionista e eugenista, mas contempla arroubos autoritários, racistas, sexistas e, politicamente, aparenta-se à ideologia nazifascista, dificulta a classificação do atual governo brasileiro por sociólogos, antropólogos, historiadores e outros estudiosos das relações humanas. Shwarcz (2019), por exemplo, propõe a palavra "democradura" para se referir a "governos que combinam de maneira perversa a regra democrática com a prática autoritária. Trata-se de seguir a norma jurídica até determinado momento, para depois escapar dela, a partir de justificativas que se desviam da lei” (2019, p. 227).

A descrição e a análise dos discursos em circulação colaboram para a identificação das ideologias e, consequentemente, das práticas sociais. No caso da violência presente na perversidade discursiva, seu potencial destrutivo só pode ser observado levando-se em conta o papel dos discursos no espaço público, ou seja, considerando-se as práticas discursivas concretas nas quais os atores sociais estão todos inseridos, conscientes ou não. 


\section{Considerações finais}

A análise da polêmica em torno das acusações de genocídio dirigidas ao governo federal brasileiro na gestão da pandemia permite demonstrar que essas declarações devem ser examinadas enquanto discurso e não somente como trocas linguísticas num modelo de comunicação restrito à transmissão de "mensagens" entre interlocutores, em uma situação restrita ao ato de fala. Trata-se de uma prática discursiva em que a violência não pode ser avaliada apenas observando-se marcas de violência verbal, mas dirigindo o olhar para a seara dos discursos, aí inclusas as disputas de poder e as posições ocupadas pelos interlocutores.

Não se trata aqui de uma avaliação ético-moralizante em termos de "bem" e "mal" ou de um desajuste entre o discurso e os valores sociais de uma época e sociedades específicas (como propõe Paveau [2015] para a análise de morais linguageiras). Trata-se de caracterizar o funcionamento atópico de um discurso eugenista fantasiado como governança de boa-fé, falsamente comprometida com o povo e cujo projeto é a morte sistemática, em massa, de grupos vulneráveis.

Esse discurso, como os demais, não pode ser resumido às falas de um indivíduo, o presidente da república (o que não significa que o ocupante da presidência não possa ser judicialmente responsabilizado), mas corresponde a uma instância que enuncia conforme as injunções do discurso ao qual está assujeitada: a doença é uma mentira, os leitos destinados às vítimas de covid-19 estão vazios, não se deve usar a máscara, a vacina é desnecessária, hidroxicloroquina é panaceia, a imprensa está contra o governo federal, os adversários políticos estão contra o Brasil, a culpa é dos governadores e dos prefeitos, a culpa é da esquerda etc.

Embora não se trate apenas de um indivíduo, a figura de JMB personifica essa perversidade discursiva: ora apresentando-se risonho, brincalhão e próximo do povo, ora sanguíneo e agressivo, ele se caracteriza pela crueldade de (tentar) dissimular o caráter autoritário, antidemocrático e eugenista do discurso que representa, em uma névoa atópica que turva a compreensão pública com mentiras, infâmia, polarização e insultos, sempre justificados com desfaçatez.

Dessa perspectiva, os empregos de "genocídio" explicitam um ponto de extrema tensão entre governados e governantes, trazendo à tona não só a gestão desumana da pandemia, mas a perversidade presente no discurso autoritário e eugenista disfarçado de democrático.

\section{Referências}


AMOSSY, Ruth. Apologia da polêmica. São Paulo: Contexto, 2017.

BARROS, Diana Luz Pessoa. Intolerância, preconceito e exclusão. In: LARA \& LIMBERTI (org) Discurso e desigualdade social. São Paulo, Contexto, 2015.

BOURDIEU, Pierre. A dominação masculina. Rio de Janeiro: Bertrand Brasil, 1998.

MAINGUENEAU, Dominique. A paratopia e suas sombras. In: Doze conceitos em Análise do Discurso. São Paulo: Parábola Editorial, 2010.

MARIN, I. S. K. Violências. São Paulo: Escuta/FAPESP, 2002.

MAUGER, Gérard. Violência simbólica. In: Vocabulário Bourdieu. São Paulo: Autêntica. pp. 359-361, 2017.

MOIRAND, Sophie. Responsabilidade e enunciação na imprensa cotidiana. In: BARONAS \& MIOTELlO (org) Análise do discurso: teorizações e métodos. São Carlos: Pedro \& João Editores, 2011.

NASCIMENTO, Abdias. O genocídio do negro brasileiro: processo de um racismo mascarado. Rio de Janeiro: Editora Paz e Terra, 1978.

OLIVEIRA, Hélio. O ethos atópico. Caderno de Estudos Linguísticos, v. 61. Campinas: Unicamp, 2019.

OLIVEIRA, Hélio. O discurso de ódio: polarização e limitação do outro. In: SALGADO, L. e VILELA-ARDERGHI, A. C. Língua, linguagens, interfaces. Belo Horizonte: Tradição Planalto, 2021.

PAVEAU, Marie-Anne. Linguagem e moral: uma ética das virtudes discursivas. Campinas, SP: Editora da Unicamp, 2015.

PIOVEZANI, Carlos; GENTILE, Emílio. A linguagem fascista. São Paulo: Hedra, 2020.

SCHWARCZ, Lilia Moritz. Sobre o autoritarismo brasileiro. São Paulo: Cia das Letras, 2019.

VAN DIJK, Teun. The violence of text and talk. Discourse \& Society, 6 (3), 1995.

VENTURA, Deisy. et al. Mapeamento e análise das normas jurídicas de resposta à covid-19 no Brasil. Direitos na pandemia. Boletim n.10. São Paulo: Universidade de São Paulo, 2021. 
7 EntreLetras Revista ENTRELETRAS (Araguaína), v. 12, n. 1, jan./abr. 2021 (ISSN 2179-3948 - online)

Encaminhado em 20 de abril de 2021. Aceito em 28 de abril de 2021. 